\title{
Spatial patterns and competition of tree species in a Douglas-fir chronosequence on Vancouver Island
}

\author{
Stephan Getzin, Charmaine Dean, Fangliang He, John A. Trofymow, Kerstin Wiegand and Thorsten Wiegand
}

Getzin, S., Dean, C., He, F., Trofymow, J. A., Wiegand, K. and Wiegand, T. 2006. Spatial patterns and competition of tree species in a Douglas-fir chronosequence on Vancouver Island. - Ecography 29: 671-682.

\begin{abstract}
While the successional dynamics and large-scale structure of Douglas-fir forest in the Pacific Northwest region is well studied, the fine-scale spatial characteristics at the stand level are still poorly understood. Here we investigated the fine-scale spatial structure of forest on Vancouver Island, in order to understand how the three dominant species, Douglas-fir, western hemlock, and western redcedar, coexist and partition space along a chronosequence comprised of immature, mature, and oldgrowth stands. We quantified the changes in spatial distribution and association of the species along the chronosequence using the scale-dependent point pattern analyses pair-correlation function $\mathrm{g}(\mathrm{r})$ and Ripley's L-function. Evidence on intra- and interspecific competition was also inferred from correlations between nearest-neighbor distances and tree size. Our results show that 1) the aggregation of Douglas-fir in oldgrowth was primarily caused by variation in local site characteristics, 2) only surviving hemlock were more regular than their pre-mortality patterns, a result consistent with strong intra-specific competition, 3) inter-specific competition declined rapidly with stand age due to spatial resource partitioning, and 4) tree death was spatially randomly distributed among larger overstory trees. The study highlights the importance of spatial heterogeneity for the long-term coexistence of shade-intolerant pioneer Douglas-fir and shade-tolerant western hemlock and western redcedar.
\end{abstract}

S. Getzin (st.getzin@uni-jena.de) and K. Wiegand, Inst. of Ecology, Univ. of Jena, Dornburger Str. 159, DE-07743 Jena, Germany. - C. Dean, Dept of Statistics and Actuarial Science, Simon Fraser Univ., Burnaby, BC V5A 1S6, Canada. - F. He, Dept of Renewable Resources, Univ. of Alberta, Edmonton, AB T6G 2H1, Canada. - J. A. Trofymow, Canadian Forest Service, Pacific Forestry Centre, 506 West Burnside Road, Victoria, BC V8Z 1M5, Canada. - T. Wiegand, Dept of Ecological Modelling, UFZCentre for Environmental Research, PF 500136, DE-04301 Leipzig, Germany.

One challenge of plant ecology is to understand how competition contributes to the patterning of plant distributions and how the patterning changes over succession. Remarkable progress has been made in using the spatial distribution of trees to infer ecological mechanisms (Ford 1975, Kenkel 1988, Duncan 1991, He and Duncan 2000, Wiegand et al. 2000), to understand the genesis and maintenance of biodiversity patterns (Plotkin et al. 2000, He and Legendre 2002, Fang 2005), and to predict stand dynamics (Mateu et al.
1998, Stoyan and Penttinen 2000, Kokkila et al. 2002). However, the fine-scale spatial distributions of trees remain poorly understood (Condit et al. 2000). Empirical studies have repeatedly shown that spatial and size distributions of trees in a community bear the fingerprint of growth, competition, and habitat heterogeneity (Ford 1975, Harms et al. 2001, Chen et al. 2004). Spatial distribution and tree size are not independent patterns but are commonly affected by competition. If competition is an important working mechanism in structuring

Accepted 27 May 2006

Copyright (C) ECOGRAPHY 2006

ISSN 0906-7590 
forest communities, two consequences should be expected: 1) there is a significantly positive correlation between tree growth (size) and nearest-neighbor distances, and 2) due to competition-induced mortality, spatial distributions of trees become more regular with time (Pielou 1962, Sterner et al. 1986, Duncan 1991, Shackleton 2002).

A simple method for detecting competition during succession is to compare the spatial patterns of a given species at subsequent stages of a chronosequence. Such a snap-shot approach using static point patterns is particularly useful in forests with slow plant growth. The pattern at late-successional series, comprising older trees that survived competition, should be more regular than that in early succession. If additional data on dead trees are available, the random mortality hypothesis can be used to detect competition. This hypothesis predicts that second-order characteristics of the spatial patterns would remain unchanged if individuals in a community are equal in death probability (Sterner et al. 1986). Opposite to this hypothesis are elevated death rates among neighboring trees due to competition. In this case, the post-mortality pattern of surviving trees becomes more regular than the pre-mortality pattern. This process is not only observed in even-aged, monoculture stands (Kenkel 1988, Newton and Jolliffe 1998) but also in uneven-aged, mixed coniferous forests (Duncan 1991, Mast and Veblen 1999, He and Duncan 2000). This method can be equally applied to infer intraspecific and inter-specific interactions. Whether the resulting spatial patterns are regular, aggregated, or random depends on the life histories of the species and on the scale at which the pattern is observed. For example, shade-intolerant and tolerant species colonize different habitats (gaps vs shades) and form segregated distributions (North et al. 2004).

However, inconsistent results are observed in some tree species (Peterson and Squiers 1995) or in more heterogeneous and older forest stands (Dovčiak et al. 2001, McDonald et al. 2003). Environmental heterogeneity, uneven age distributions, limited dispersal of seeds or random germination may prevent a pattern from becoming more regular even though competition is present (Kenkel 1988). Moreover, sometimes competition may not be strong enough to cause substantial mortality but just cause growth reduction. In such situations where spatial patterns are ambiguous about competition, the correlation between tree size and neighborhood density provides a useful measurement (Shackleton 2002).

In this article, we use spatial pattern analysis to infer, from the fine-scale spatial distributions of trees, how the dominant tree species in a forest compete and partition space, and how their spatial interactions change during succession. More specifically, we analyze the successional dynamics of shade-intolerant pioneer Douglas-fir
Pseudotsuga menziesii var. menziesii and of two shadetolerant late-successional species, western hemlock Tsuga heterophylla and western redcedar Thuja plicata in a chronosequence in the Pacific Northwest region on south-eastern Vancouver Island.

To understand the change in spatial structure and species interactions in Douglas-fir forests across spatial and temporal scales, we first present the stand structural characteristics of the forests and infer intraspecific and inter-specific competition from correlations between tree size and nearest-neighbor distances before performing detailed point pattern analyses. Positive correlation between tree size and nearest-neighbor distances is expected if competition reduces growth. Evidence relating particularly to competition-induced mortality can be obtained from uni- and bivariate spatial patterns. More regular distribution in postmortality pattern of surviving trees is expected if intra-specific competition leads to mortality. Similarly, strong inter-specific competition between shade-intolerant Douglas-fir and shade-tolerant western hemlock and western redcedar is expected to separate Douglasfir from the two shade-tolerant species in space. Once trees have reached the upper canopy layer, their mortality should be unaffected by competition from smaller neighbors. Thus, we also test whether tree death among larger trees of the overstory is spatially correlated, or a random process.

\section{Methods}

\section{Study sites and data collection}

The chronosequence is located in the drier coastal temperate forest found on leeward side of south-eastern Vancouver Island within the Greater Victoria Watershed District $\left(48^{\circ} 33^{\prime} \mathrm{N}, 123^{\circ} 38^{\prime} \mathrm{W}\right)$. All stands studied were within the eastern variant of the Very Dry Maritime subzone of the Coastal Western Hemlock zone (CWHxm1), which has mild and wet winters, warm and dry summers, a mean annual precipitation of 1425 $\mathrm{mm}$, and a mean annual temperature of $9.4^{\circ} \mathrm{C}$ (Green and Klinka 1994). Pioneer Douglas-fir (Df) is the dominating tree species and western hemlock (Hw) and western redcedar $(\mathrm{Cw})$ are two primary late-successional species that usually aggregate in gaps (Fig. 1). Other minor components include, e.g. western white pine Pinus monticola or red alder Alnus rubra. The chronosequence consists of an immature (IM), mature (MA) and oldgrowth (OG) stand with ages varying from 39 (IM), 109 (MA) to $254 \mathrm{yr}(\mathrm{OG})$ at the time of data collection in 1999 and 2000. The stands are located on gentle to moderate slopes with elevations ranging from 240 to $390 \mathrm{~m}$. Due to some rock outcrops, slight spatial heterogeneity was present in the plots. The immature stand was originally regenerated from artificial planting 
Fig. 1. Maps of the immature (A), mature (B), and oldgrowth (C) plots. Open symbols are live trees: Douglas-fir $(\bigcirc)$, western hemlock $(\Delta)$, western redcedar $(\square)$, and other species $(\triangleright)$. Respective symbols with grey color filling are dead trees. Symbol sizes are proportional to the DBH. Smallest dots represent trees with a $\mathrm{DBH} \leq 5$ $\mathrm{cm}$, the largest circle in oldgrowth $(\mathrm{C})$ is a Douglas-fir with a DBH of $1.60 \mathrm{~m}$.
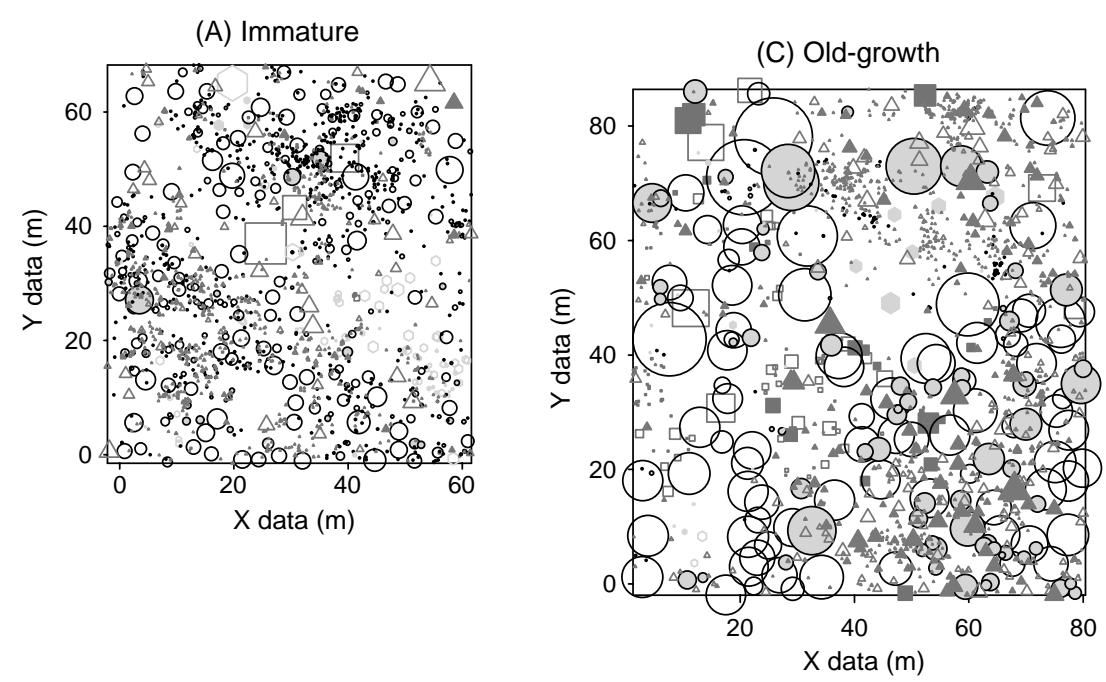

(B) Mature

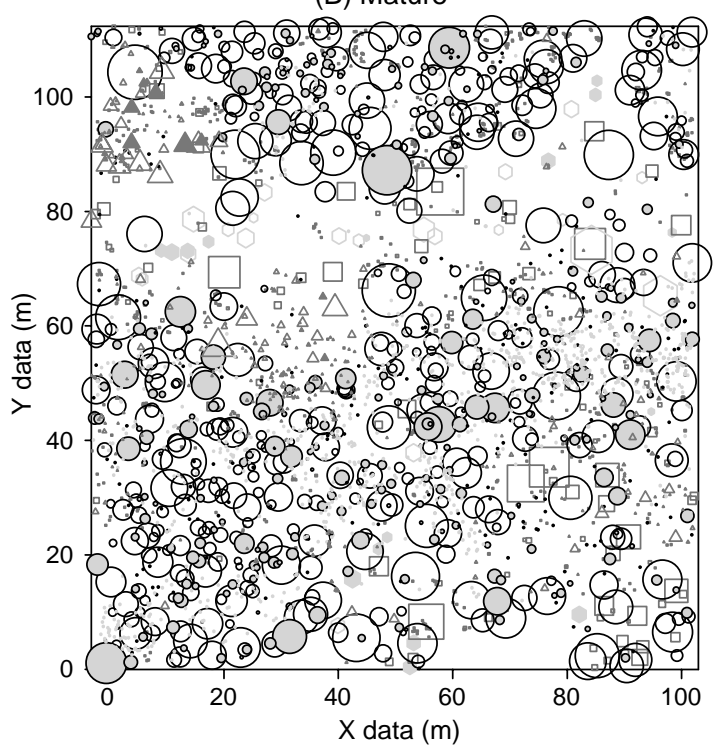

of Douglas-fir seedlings after harvesting and broadcast burn. However, the majority of Douglas-fir individuals in this plot are already naturally regenerated offspring from the planted trees. All other species were naturally regenerated. The mature stand originated naturally from wildfire followed by some salvage logging. The oldgrowth plot originated from a catastrophic wildfire. Further information on site characteristics and plot locations can be found in Trofymow et al. (1997), including the descriptions pertaining to plots 2 (IM), 5 (MA), and 6 (OG). Data were collected on $0.5-1.2$ ha plots. All dead and live trees, including seedlings were stem-mapped. Diameter at breast height (DBH) of each live tree was measured at $1.4 \mathrm{~m}$ above ground, and all individuals were identified to species.

\section{Data analysis}

\section{1) Stand structure and composition}

The mean nearest-neighbor distance for each species in each plot was calculated using $\mathrm{S}+$ SpatialStats. The number of stems $(\mathrm{N})$ and relative proportion $(\%)$ of live and dead trees of each species were counted for the three dominant species $\mathrm{Df}, \mathrm{Hw}$, and $\mathrm{Cw}$. $\mathrm{Cw}$ was not analyzed for the IM plot because its proportion was below 3\%. We also calculated the mean DBH for each species in the plots, the species proportions within their smallest DBH class of $0.1-10 \mathrm{~cm}$, and the proportion of dead trees of a species within this small diameter class.

Pielou's segregation index $\mathrm{S}$ was calculated for these species to quantify their relative spatial mixing (Pielou 
1961). The index $\mathrm{S}$ was computed from the properties described in Table 1 as, $S=1-\frac{M_{O}}{M_{E}}=1-\frac{N(b+c)}{v n+w m}$, where $\mathrm{M}_{\mathrm{O}}$ is the observed number of mixed nearest neighbor pairs and $\mathrm{M}_{\mathrm{E}}$ is the expected number under random conditions (Kint et al. 2003). Under segregation, values of $\mathrm{S}$ range between 0 and 1 , with 1 indicating highest spatial separation. In communities of more than two dominant species $\mathrm{S}$ was calculated by comparing one species against all other species in the plot.

\section{2) Correlations between tree size and nearest-neighbor distances}

For each of the three species and for each successional stage, we analyzed the correlation between the sum of the DBH of the four nearest neighbors plus the DBH of the focal tree and the sum of the distances of the four nearest neighbors to that focal tree (Shackleton 2002). The coefficient of determination $r^{2}$ describes the relative importance of competition as an agent in structuring the forest community (Welden and Slauson 1986). Although one cannot derive causal links from regression analyses, $r^{2}$ has been shown to be a robust index of competition, despite the complexity of biotic and abiotic factors influencing forest structure (Welden et al. 1988). In this paper, "nearest neighbors" refers to the four nearest neighbors of a focal tree, trees with a "conspecific neighborhood" have three or four conspecific nearest neighbors and trees with a "heterospecific neighborhood" have none or one conspecific nearest neighbor. The size-distance correlation was conducted for inferring species, intra-specific, and inter-specific competition by including only the following subset of focal trees in the analysis: all focal trees of a given species, focal trees with a conspecific neighborhood, and focal trees with heterospecific neighborhood, respectively. We then plotted the importance of species, intra-, and inter-specific competition (measured by $\mathrm{r}^{2}$ ) against stand age.

To measure how well species survive intra- and interspecific competition during different successional stages, we compared the proportion of dead trees for each of the three species with a difference test, once between their con- and heterospecific neighborhoods and once between the species only in heterospecific neighborhoods. We also compared both, mean distance and mean DBH of the four nearest-neighbors by means of a two-sided t-test.

Table 1. Contingency table, defining the types of nearestneighbor relationships between species $\mathrm{A}$ and $\mathrm{B}$, for calculating Pielou's S.

\begin{tabular}{lccc}
\hline & \multicolumn{3}{c}{ No. of nearest neighbors of } \\
\cline { 2 - 4 } & species A & species B & species A+B \\
\hline Species A & a & b & $\mathrm{m}$ \\
Species B & c & d & $\mathrm{n}$ \\
Species A+B & v & w & N \\
\hline
\end{tabular}

\section{3) Spatial pattern analysis}

We used the pair-correlation function $\mathrm{g}(\mathrm{r})$, which is a distance-dependent correlation function for completely mapped point patterns (Stoyan and Stoyan 1994, Wiegand and Moloney 2004). Based on point-to-point distances, the g-function describes clumping and regularity at a given radius $\mathrm{r}$, using a standardized density. Consequently, $\mathrm{g}(\mathrm{r})=1$ under complete spatial randomness (CSR), $\mathrm{g}(\mathrm{r})>1$ indicates aggregation, while $\mathrm{g}(\mathrm{r})<1$ indicates regularity. The univariate pair-correlation function $\mathrm{g}(\mathrm{r})$ is related to the derivative of the widely used K-function (Ripley 1976), i.e. $\mathrm{K}(\mathrm{r})=2 \pi \int_{0}^{\mathrm{r}} \mathrm{g}\left(\mathrm{r}^{\prime}\right) \mathrm{r}^{\prime} \mathrm{dr}^{\prime}$ and can be interpreted as the expected density of points at a given distance $r$ of an arbitrary point, divided by the intensity $\lambda$ of the pattern (Stoyan and Stoyan 1994, Dale et al. 2002). Similar to the K-function, g(r) can also be extended to describe point patterns with two types of points (e.g. dead and live trees): the bivariate paircorrelation function $\mathrm{g}_{12}(\mathrm{r})$ is the expected density of points of pattern 2 at distance $r$ of an arbitrary point of pattern 1 , divided by the intensity $\lambda_{2}$ of pattern 2 .

Compared with Ripley's K-function, which has a character comparable with that of a distribution function, $g(r)$ has a character comparable with that of a probability density function and is considered more powerful in detecting spatial patterns across scales (Wiegand and Moloney 2004). This is because $\mathrm{g}(\mathrm{r})$ has the advantage of isolating specific distance classes and can therefore be used to precisely determine spatial scales at which a given null model is violated. In contrast, $\mathrm{K}(\mathrm{r})$ is a cumulative distribution function that calculates point densities within the entire circle of a given radius (Ripley 1976). Therefore, it confounds the effect at large distances with the effect of small distances (memory effect), which can complicate its interpretation (Condit et al. 2000, Schurr et al. 2004). However, K(r) or its transformation $\mathrm{L}(\mathrm{r})$ is more pertinent for the confirmation of null models (Stoyan and Penttinen 2000).

In this study we used both $\mathrm{g}(\mathrm{r})$ to analyze the finescale spatial patterns and $\mathrm{L}(\mathrm{r})$ for the confirmation (not shown) of underlying null models (Table 2). These functions were computed using the grid-based software Programita for point pattern analysis (Wiegand and Moloney 2004). Significant departure from an underlying null model was tested by 99 Monte Carlo simulations which generates $\mathrm{n} /(\mathrm{n}+1) \times 100 \%$, hence $99 \%$ confidence limits (Bailey and Gatrell 1998).

To investigate whether the basic pattern of all (dead and live) trees of a species would become more regularly distributed during succession, we implemented a null model based on a heterogeneous Poisson process. A heterogeneous Poisson process was chosen because our plots were partly influenced by first-order heterogeneity (Fig. 1), hence the intensity $\lambda$ is not approximately constant but varies with the location $(\mathrm{x}, \mathrm{y})$. We used a circular moving window with a fixed bandwidth $\mathrm{R}$ to 
Table 2. Hypotheses, applied point pattern analyses, and related figures used in this study.

\begin{tabular}{|c|c|c|}
\hline Hypotheses & $\begin{array}{l}\text { Point pattern analyses; null } \\
\text { hypotheses applied }\end{array}$ & $\begin{array}{l}\text { Related } \\
\text { figures }\end{array}$ \\
\hline $\begin{array}{l}\text { 1) The spatial pattern of all dead and } \\
\text { live Douglas-fir becomes regular during } \\
\text { succession. }\end{array}$ & $\begin{array}{l}\text { Pair-correlation function } \mathrm{g}(\mathrm{r}) \text {, } \\
\text { heterogeneous Poisson null model; CSR } \\
\text { only within moving window } \mathrm{R}=10 \mathrm{~m} \text {. }\end{array}$ & Fig. $3 \mathrm{~A}-\mathrm{H}$ \\
\hline $\begin{array}{l}\text { 2) Intra-specific competition leads to a more } \\
\text { regular post-mortality pattern of surviving trees, } \\
\text { which is indicative of self-thinning. }\end{array}$ & $\begin{array}{l}\text { Univariate random labeling with } \mathrm{g}_{11}(\mathrm{r}) \text {; live trees } \\
\text { are a random subset of pre-mortality pattern (dead } \\
\text { and live trees). }\end{array}$ & Fig. $4 \mathrm{~A}-\mathrm{H}$ \\
\hline $\begin{array}{l}\text { 3) Inter-specific competition between } \\
\text { shade-intolerant Douglas-fir and shade-tolerant } \\
\text { species (western hemlock and western redcedar) } \\
\text { leads to interspecific repulsion. }\end{array}$ & $\begin{array}{l}\text { Bivariate analysis with } \mathrm{g}_{12}(\mathrm{r}) \text { and the toroidal shift } \\
\text { null model; no spatial correlation between Douglas-fir } \\
\text { (pattern 1) and shade-tolerant species (pattern 2). }\end{array}$ & Fig. $5 \mathrm{~A}-\mathrm{C}$ \\
\hline $\begin{array}{l}\text { 4) Tree death of larger overstory trees is a spatial } \\
\text { random process at each succession stage. }\end{array}$ & $\begin{array}{l}\text { Bivariate random labeling with } \mathrm{g}_{21}(\mathrm{r})-\mathrm{g}_{22}(\mathrm{r}) \text {; } \\
\text { no spatial correlation of larger dead trees (pattern } 2) \text {. }\end{array}$ & Fig. $6 \mathrm{~A}-\mathrm{C}$ \\
\hline
\end{tabular}

estimate $\lambda(\mathrm{x}, \mathrm{y})$. Hence, patterns may be interpreted up to a radius of $\mathrm{R}=10 \mathrm{~m}$ only (Wiegand and Moloney 2004; Hypothesis 1, Table 2).

For the random mortality hypothesis, we used univariate random labeling as null model to investigate whether the $\mathrm{n}_{1}$ live trees of a species (post-mortality pattern) are a random subset of the pre-mortality pattern, i.e. the joined pattern of dead $\left(n_{2}\right)$ and live $\left(\mathrm{n}_{1}\right)$ trees. The test was conducted by computing the function $\mathrm{g}_{11}(\mathrm{r})$ from the observed data, then randomly re-sampling sets of dead trees from the joined pattern of live and dead trees to generate the confidence limits. This null model also accounts for first-order heterogeneity (Hypothesis 2, Table 2).

To investigate the interaction between shade-intolerant Df and late-successional, shade-tolerant species, we used the toroidal shift null model (independence), in which the second-order structure of both patterns is preserved but shifted relative to each other. We directly compared Df and Hw in the IM plot with each other. In other plots where more than one shade-tolerant species dominated, Df was compared against all other species. These analyses were conducted once for all (live and dead) trees and once for live trees only (Hypothesis 3, Table 2).

To investigate the mortality of larger trees, we used bivariate random labeling with $\mathrm{g}_{21}(\mathrm{r})-\mathrm{g}_{22}(\mathrm{r})$. Under random labeling, g-functions are invariant, hence we would expect $\mathrm{g}_{12}(\mathrm{r})=\mathrm{g}_{21}(\mathrm{r})=\mathrm{g}_{11}(\mathrm{r})=\mathrm{g}_{22}(\mathrm{r})$. Departure from random labeling is assessed using specific combinations of pairwise differences that correspond to specific biological effects. If $\mathrm{g}_{21-} \mathrm{g}_{22}<0$ at radius $r$, then type 2 points (dead trees) are relatively more frequent around type 2 points than type 1 points (live trees) around type 2 points, hence dead trees are positively correlated at radius $\mathrm{r}$. We included all trees with $\mathrm{DBH}>10 \mathrm{~cm}$ in the IM, $>20 \mathrm{~cm}$ in the MA, and $>30 \mathrm{~cm}$ in the OG plots (Hypothesis 4, Table 2). Both bivariate null models (toroidal shift and random labeling) are very robust and produce reliable results when the heterogeneity of the plot is slight (Diggle and Chetwynd 1991, Wiegand and Moloney 2004).

\section{Results}

\section{1) Stand structure and composition}

Douglas-fir. The relative species frequency of Df declined during succession from 49.9 to $16.7 \%$ (Table 3). Also, its mortality declined with increasing stand age from $56.8 \%$ in the IM plot to $36.5 \%$ in the OG plot. Its mean DBH increased with stand age from 8.2 to $52.2 \mathrm{~cm}$. Compared to other species, Df consistently had the

Table 3. Stand structure and composition of the chronosequence. \langle\rangle$=$ mean, $\mathrm{NN}=$ nearest neighbor; $\mathrm{S}=$ Pielou's segregation index.

\begin{tabular}{|c|c|c|c|c|c|c|c|c|}
\hline $\begin{array}{l}\text { Plot/ } \\
\text { species }\end{array}$ & $\begin{array}{c}\langle\mathrm{NN}\rangle \\
\text { distance } \\
(\mathrm{m}) \text { in plot }\end{array}$ & $\begin{array}{l}\text { Number } \\
\text { of } \\
\text { stems }\end{array}$ & $\%$ stems & $\begin{array}{l}\% \text { mortality } \\
\text { per species }\end{array}$ & $\begin{array}{c}\langle\mathrm{DBH}\rangle \\
(\mathrm{cm}) \\
\text { per species }\end{array}$ & $\begin{array}{l}\% \text { with DBH } \\
\text { of } 0.1-10 \mathrm{~cm}\end{array}$ & $\begin{array}{c}\% \text { mortality } \\
\text { within DBH } \\
\text { class of } 0.1-10 \mathrm{~cm}\end{array}$ & Pielou's S \\
\hline Immature & 0.63 & & & & & & & \\
\hline Douglas-fir & & 885 & 49.9 & 56.8 & 8.2 & 74.0 & 60.8 & 0.296 \\
\hline Western hemlock & & 750 & 42.3 & 71.7 & 5.4 & 86.6 & 75.6 & 0.318 \\
\hline Mature & 0.82 & & & & & & & \\
\hline Douglas-fir & & 875 & 28.9 & 50.1 & 33.7 & 6.5 & 95.5 & 0.193 \\
\hline Western hemlock & & 381 & 12.6 & 19.7 & 10.0 & 65.7 & 23.9 & 0.398 \\
\hline Western redcedar & & 720 & 23.8 & 5.3 & 7.8 & 80.5 & 5.1 & 0.567 \\
\hline Old-growth & 0.93 & & & & & & & \\
\hline Douglas-fir & & 244 & 16.7 & 36.5 & 52.2 & 15.3 & 44.4 & 0.350 \\
\hline Western hemlock & & 1061 & 72.6 & 40.3 & 11.0 & 59.0 & 57.3 & 0.485 \\
\hline Western redcedar & & 130 & 8.9 & 24.6 & 19.9 & 36.0 & 21.9 & 0.600 \\
\hline
\end{tabular}


lowest segregation index in each plot and was thus spatially least separated (Table 3 ).

Western hemlock. The species proportion of Hw was intermediate in the IM plot, low in the MA plot but high in the OG plot (Table 3). Its proportion in the smallest DBH class of $0.1-10 \mathrm{~cm}$ was highest $(86.6 \%)$ due to the initial colonization in the IM plot, but lowest in the OG plot. In each succession stage, Hw was spatially more separated than Df but less than Cw (Table 3).

Western redcedar. This species was virtually absent from the immature plot but started to colonize at the mature succession stage, as indicated by both its overall proportion $(23.8 \%)$ and its high proportion in the smallest DBH class of $0.1-10 \mathrm{~cm}(80.5 \%)$ in the MA plot (Table 3). Its mortality was always lowest in this small size class. $\mathrm{Cw}$ had the highest segregation index within a plot, and thus was spatially more separated than other species.

\section{2) Correlations between tree size and nearest- neighbor distances}

Douglas-fir. The relative importance of competition for Df as whole group as well as intra-specific competition declined from the IM plot to the MA plot but increased strongly in the OG plot (Fig. 2A-B). Inter-specific competition of Df declined constantly with increasing stand age (Fig. 2C). There was no significant difference in mortality of Df within con- or heterospecifics, neither in the IM nor in the MA plot, but intra-specific mortality was significantly lower than inter-specific mortality in the OG plot (Table 4A).

Western hemlock. The temporal pattern of competition of $\mathrm{Hw}$ is similar to Df. Competition of $\mathrm{Hw}$ as a whole species group and intra-specific competition within conspecifics declined from the IM plot to the MA plot but increased in the OG plot (Fig. 2A-B). Similar to Df, inter-specific competition of $\mathrm{Hw}$ declined with increasing stand age. Inter-specific competition was strong for hemlock in the IM plot, as indicated by the high coefficient of determination (0.59) (Fig. 2C). Unlike Df, inter-specific mortality of Hw was significantly lower than intra-specific mortality in the IM and MA plots (Table 4A). In comparison to $\mathrm{Df}$, the strength of $\mathrm{Hw}$ as a shade-tolerant colonizer is also reflected in the four times lower interspecific mortality of $\mathrm{Hw}$ in the MA plot, although $\mathrm{Hw}$ was surrounded by significantly larger trees than Df (Table 4B).

Western redcedar. Competition of $\mathrm{Cw}$ as a whole species group and intra-specific competition declined from the MA plot to the OG plot (Fig. 2A-B). Similar to Df, intra-specific and inter-specific mortality was not significantly different for $\mathrm{Cw}$ during its initial colonization in the MA plot. However, it had a significantly
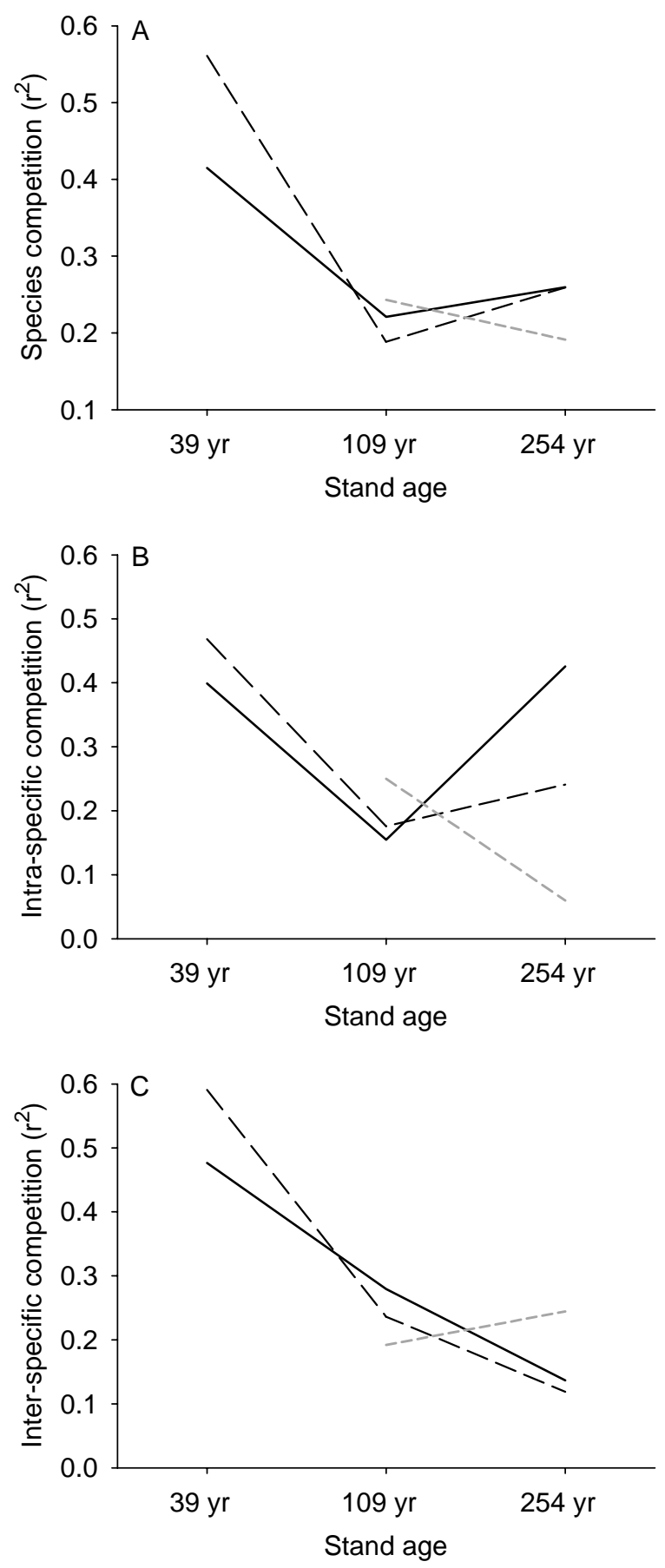

Fig. 2. The importance of competition for Douglas-fir (western hemlock $(--)$, and western redcedar $(---)$ as whole groups (A), without distinguishing between con- and heterospecific neighborhoods. Intra-specific (B), and inter-specific (C) competition of the species in con- and heterospecific neighborhoods, respectively.

lower inter-specific mortality (3.3\%) than Df and $\mathrm{Hw}$, although $\mathrm{Cw}$ was in both cases surrounded by significantly larger trees (Table 4B). 
Table 4. Pairwise comparison of mortality, nearest neighbor distances (NN), and surrounding tree size (DBH). (A) within the same species undergoing intra- and inter-specific competition and (B) between two species undergoing inter-specific competition. There were not enough data for redcedar in the immature plot. $\left({ }^{*}=\right.$ significant at $\left.\mathrm{p}<0.05 ;{ }^{* *} \mathrm{p}<0.01 ;{ }^{\wedge} \mathrm{p}=0.052 ;{ }^{\wedge} \mathrm{p}=0.057\right)$.

\begin{tabular}{|c|c|c|c|c|c|c|}
\hline Plot/attribute & Df intra & Df inter & Hw intra & Hw inter & $\mathrm{Cw}$ intra & $\mathrm{Cw}$ inter \\
\hline \multicolumn{7}{|l|}{ (A) Within species } \\
\hline \multicolumn{7}{|l|}{ Immature } \\
\hline Mortality (\%) & 48.6 & 50.3 & 77.1 & $53.8 * *$ & & \\
\hline$\langle 4 \mathrm{NN}$ dist. $\rangle$ (m) & 4.85 & 4.87 & 3.45 & $5.36^{* *}$ & & \\
\hline$\langle 4 \mathrm{DBH}\rangle(\mathrm{cm})$ & 24.8 & 24.3 & & $30.9^{* *}$ & & \\
\hline \multicolumn{7}{|l|}{ Mature } \\
\hline Mortality (\%) & 40.9 & 39.4 & 33.3 & $10.0 * *$ & 4.2 & 3.3 \\
\hline$\langle 4 \mathrm{NN}$ dist. $\rangle(\mathrm{m})$ & 9.44 & $8.25^{* *}$ & 7.23 & $8.46^{* *}$ & 5.83 & $8.83^{* *}$ \\
\hline$\langle 4 \mathrm{DBH}\rangle(\mathrm{cm})$ & 112.7 & $43.9 * *$ & 42.0 & $70.2 * *$ & 39.1 & $89.8^{* *}$ \\
\hline \multicolumn{7}{|l|}{ Old-growth } \\
\hline Mortality (\%) & 24.0 & $51.4^{*}$ & 53.8 & 62.3 & 17.9 & $41.2^{\wedge}$ \\
\hline$\langle 4 \mathrm{NN}$ dist. $\rangle(\mathrm{m})$ & 11.39 & $9.47 *$ & 6.86 & $10.90^{* *}$ & 9.23 & $11.21^{*}$ \\
\hline$\langle 4 \mathrm{DBH}\rangle(\mathrm{cm})$ & 166.8 & $65.4^{* *}$ & 50.6 & $110.3^{* *}$ & 62.3 & $96.4^{* *}$ \\
\hline Plot/attribute & Df inter & Hw inter & Df inter & $\mathrm{Cw}$ inter & $\mathrm{Hw}$ inter & $\mathrm{Cw}$ inter \\
\hline \multicolumn{7}{|l|}{ (B) Between species } \\
\hline \multicolumn{7}{|l|}{ Immature } \\
\hline Mortality (\%) & 50.3 & 53.8 & & & & \\
\hline$\langle 4 \mathrm{NN}$ dist. $\rangle(\mathrm{m})$ & 4.87 & 5.36 & & & & \\
\hline$\langle 4 \mathrm{DBH}\rangle(\mathrm{cm})$ & 24.3 & $30.9 * *$ & & & & \\
\hline \multicolumn{7}{|l|}{ Mature } \\
\hline Mortality (\%) & 39.4 & $10.0^{* *}$ & 39.4 & $3.3 * *$ & 10.0 & $3.3^{*}$ \\
\hline$\langle 4 \mathrm{NN}$ dist. $\rangle$ (m) & 8.25 & 8.46 & 8.25 & 8.83 & 8.46 & 8.83 \\
\hline$\langle 4 \mathrm{DBH}\rangle(\mathrm{cm})$ & 43.9 & $70.2^{* *}$ & 43.9 & $89.8^{* *}$ & 70.2 & $89.8^{* *}$ \\
\hline \multicolumn{7}{|l|}{ Old-growth } \\
\hline Mortality (\%) & 51.4 & 62.3 & 51.4 & 41.2 & 62.3 & $41.2^{\wedge \wedge}$ \\
\hline$\langle 4 \mathrm{NN}$ dist. $\rangle$ (m) & 9.47 & $10.90^{*}$ & 9.47 & $11.21^{*}$ & 10.90 & 11.21 \\
\hline$\langle 4 \mathrm{DBH}\rangle(\mathrm{cm})$ & 65.4 & $110.3^{* *}$ & 65.4 & $96.4 * *$ & 110.3 & 96.4 \\
\hline
\end{tabular}

\section{3) Spatial pattern analysis}

\section{Univariate patterns}

Douglas-fir. Pre-mortality Df (dead + live) aggregated up to $5.5 \mathrm{~m}$ in the IM plot, were randomly distributed in the MA plot, and showed a strong small-scale aggregation at scales $\leq 2 \mathrm{~m}$ in the OG plot (Fig. $3 \mathrm{~A}-\mathrm{C}$ ). The random mortality hypothesis could not be rejected for Df in the IM and MA plots (Fig. 4A-B). However, the distribution of live Df in the OG plot was aggregated at scales up to $2.5 \mathrm{~m}$ (Fig. 4C).

Western hemlock. Pre-mortality patterns of Hw were aggregated in all plots (Fig. 3D-F), with the strongest aggregation in old-growth. In comparison to the premortality patterns, surviving $\mathrm{Hw}$ (post-mortality) were partly regularly distributed in the IM and MA plots, showing strong evidence of self-thinning, but were more aggregated in the OG plot (Fig. 4D-F).

Western redcedar. All $\mathrm{Cw}$ were strongly aggregated in the MA and OG plots (Fig. $3 \mathrm{G}-\mathrm{H}$ ). The post-mortality pattern was random in the MA plot but aggregated in the OG plot (Fig. $4 \mathrm{G}-\mathrm{H})$.

\section{Bivariate patterns}

Inter-specific competition between shade-intolerant Douglas-fir and shade-tolerant species was not detectable via regular distributions from point pattern analysis. $\mathrm{Hw}$ aggregated strongly at the smallest scale around Df in the IM plot (Fig. 5A), but with the increase in stand age, the spatial association of other species around Df disappeared (Fig. 5A-C). Analyses with only live trees revealed the same results (not shown).

Tree death was spatially randomly distributed among larger overstory trees in the IM and MA plots (Fig. 6AB). However, there was a significant positive correlation for dead trees at distances up to $1.5 \mathrm{~m}$ in the $\mathrm{OG}$ plot (Fig. 6C). This was probably a size class effect because most dead trees had a DBH of $30-40 \mathrm{~cm}$. To exclude such size class effect, one would have to exclusively look at DBH classes above $40 \mathrm{~cm}$. But there were too few trees in this large size class in the OG plot to permit a reliable statistical analysis.

\section{Discussion}

\section{Spatial patterns and competition}

Using scale-dependent spatial statistics, small-scale negative interactions among Douglas-fir trees have been observed on Vancouver Island (He and Duncan 2000). In contrast, our analysis of a chronosequence of Douglas-fir forest showed aggregation at distances below $6 \mathrm{~m}$, which indicates a positive interaction at small spatial scales. Moreover, the degree of spatial aggregation and the importance of competition were positively linked in our study (cf. Fig. 3 vs Fig. 2A). For Douglas-fir and hemlock, spatial aggregation and 

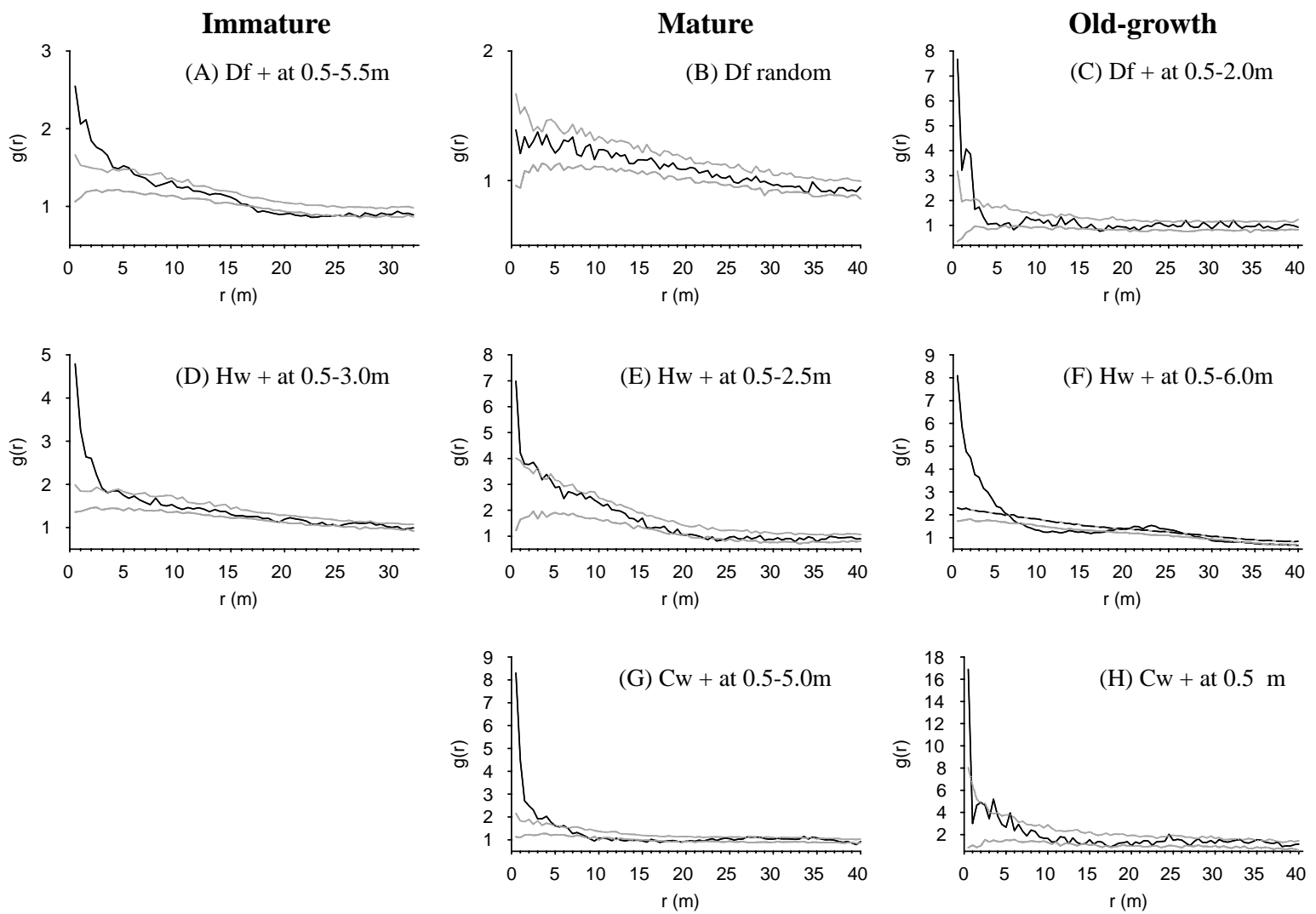

Fig. 3. Univariate analyses of the overall (pre-mortality) patterns of dead and live Douglas-fir (A, B, C), western hemlock (D, E, F) and western redcedar $(\mathrm{G}, \mathrm{H})$, using $\mathrm{g}(\mathrm{r})$ and the heterogeneous Poisson null model with a moving window of $\mathrm{R}=10 \mathrm{~m}$. The largescale heterogeneity was well captured by the null model at scales beyond $\mathrm{R}=10 \mathrm{~m}$, but deviation from CSR occurred within the moving window. Significant aggregation is indicated by a " $+" .(\mathrm{g}(\mathrm{r})=$ black solid line; $99 \%$ upper and lower confidence limits $=$ grey lines).

competition were highest in the immature and oldgrowth plots but lowest in the mature plot. Likewise, the pattern of redcedar was more aggregated and competition more important in the mature plot, as compared to old-growth. Here, we suggest that competition during the long time span of succession does not necessarily need to result in small-scale regularity of whole species patterns and propose three reasons for that observation.

Firstly, a positive link between competition and aggregation may arise when competitive thinning of large trees leads to gaps in which clustered offspring regenerate. This has been proposed by Pileou (1962) and was recently supported by a forest model (Moravie and Robert 2003). Under such circumstances, the overall pattern of a species is only indirectly influenced by mortality of large trees but directly determined by the pattern of gap recruitment of small competing trees (Simard and Sachs 2004, Wolf 2005). This did not occur with Douglas-fir in the homogeneous old-growth plot of He and Duncan (2000), because canopy gaps are usually not large enough for shade-intolerant Douglas-fir to regenerate underneath. However, with $500 \mathrm{~mm}$ less precipitation per year our chronosequence was much drier, and on dry sites gaps may reach sizes that lead to clustered regeneration of Douglas-fir (Spies et al. 1990).

Secondly, spatial heterogeneity induced by edaphic gaps may cause a patchy (clumped) size class distribution, thereby masking the tendency towards regular growth patterns (Sterner et al. 1986, Dovčiak et al. 2001). Such gaps often have sufficient sizes for regeneration and pioneer species like Douglas-fir may re-colonize the gap peripheries after other species have died due to wind throw (Lertzman et al. 1996). Besides temporal disturbances by fire (Franklin and DeBell 1988), spatial heterogeneity may be crucial for the long-term persistence of shade-intolerant pioneer Douglas-fir during succession. This assumption is supported by the lower mortality $(36.5 \%)$ of Douglas-fir in our heterogeneous old-growth stand, as compared to its higher mortality $(47.8 \%)$ in the homogeneous old-growth stand of He and Duncan (2000). Whereas the spatial pattern of western hemlock and western redcedar is typically aggregated (Keeton and Franklin 2005), the pattern of Douglas-fir seems to be largely dependent on the degree of spatial variation in local dryness and edaphic heterogeneity. In 
Immature
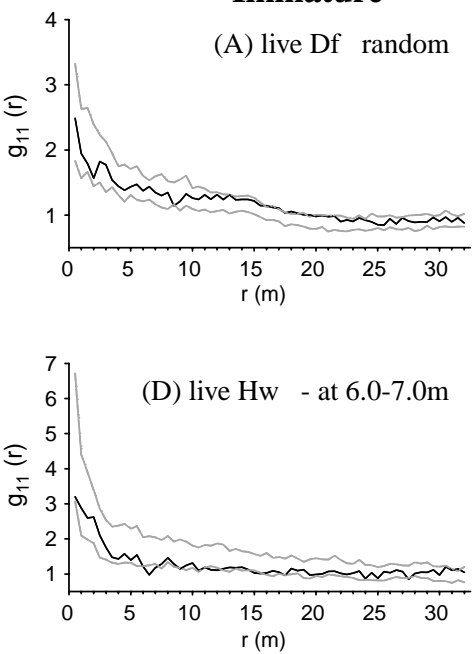

Mature
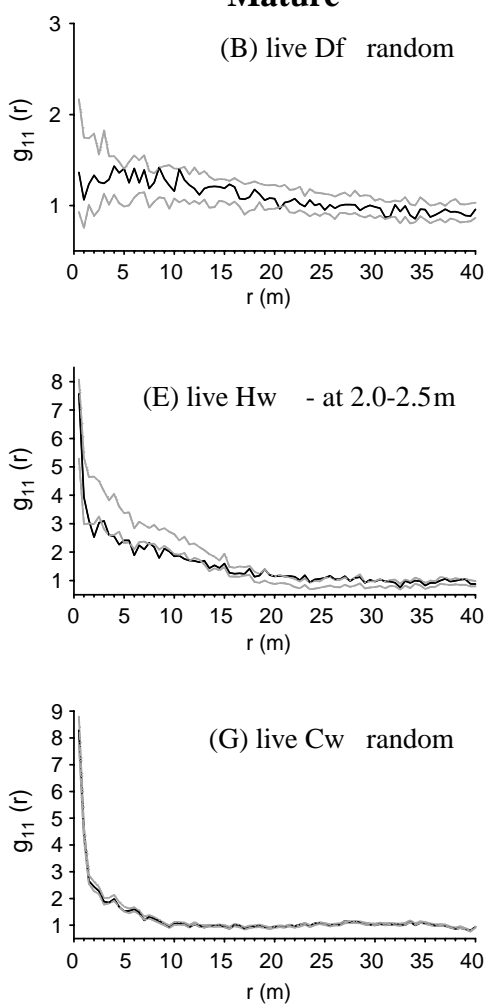

Old-growth
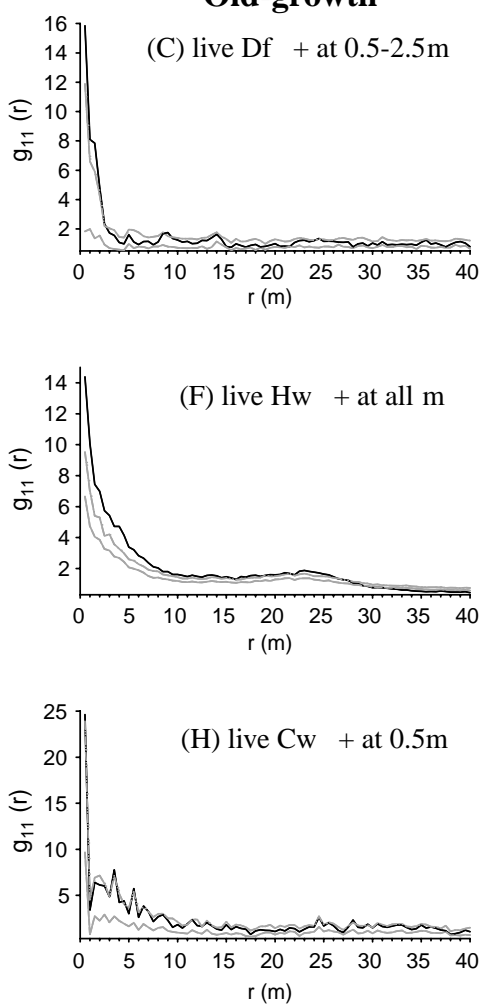

Fig. 4. Univariate analyses of the post-mortality patterns of live Douglas-fir (A, B, C), western hemlock (D, E, F), and western redcedar $(\mathrm{G}, \mathrm{H})$, using univariate random labeling $\left(\mathrm{g}_{11}\right)$ as null model which also accounts for the heterogeneity.

agreement with results from other forest types (McDonald et al. 2003), we highlight the importance of variation in local site characteristics and site history for the unexpected small-scale clumping of Douglas-fir in our old-growth stand.

Thirdly, a reason for the lack of evidence of spatial regularity despite finding important competition via size correlations is that competition may not be strong enough to cause mortality but just to reduce growth. Only when competition leads to sufficient mortality within a species pattern, it will cause regular distributions (Stoll and Bergius 2005). Also, species may have differential abilities to cope with intra-and inter-specific competition. To account for such confounding effects on the spatial pattern of species, it is important to look at intra- and inter-specific competition within a succession stage.

\section{Intra-specific competition}

Previous studies have shown that post-mortality patterns of surviving trees were more regular than expected under random-thinning (Sterner et al. 1986, Kenkel 1988, Duncan 1991, He and Duncan 2000). In this case,
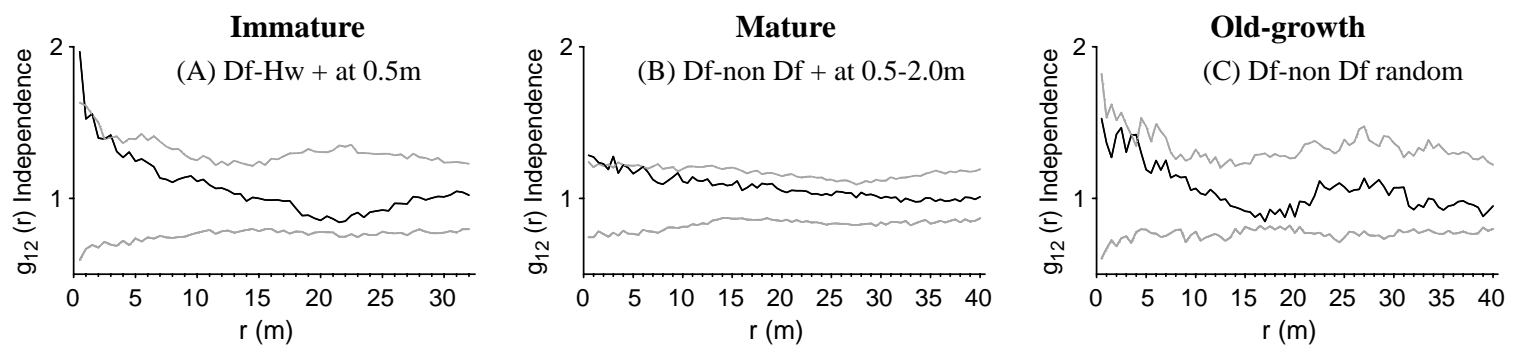

Fig. 5. Bivariate analysis of all hemlock (pattern 2) around all Douglas-fir (pattern 1) in the immature plot (A), using $\mathrm{g}_{12}(\mathrm{r})$ and the toroidal shift null model. In the mature and old-growth plots $(\mathrm{B}, \mathrm{C})$ more than one shade-tolerant species was dominating. Therefore, at each time, we used all other species as pattern 2 and Douglas-fir as pattern 1. 

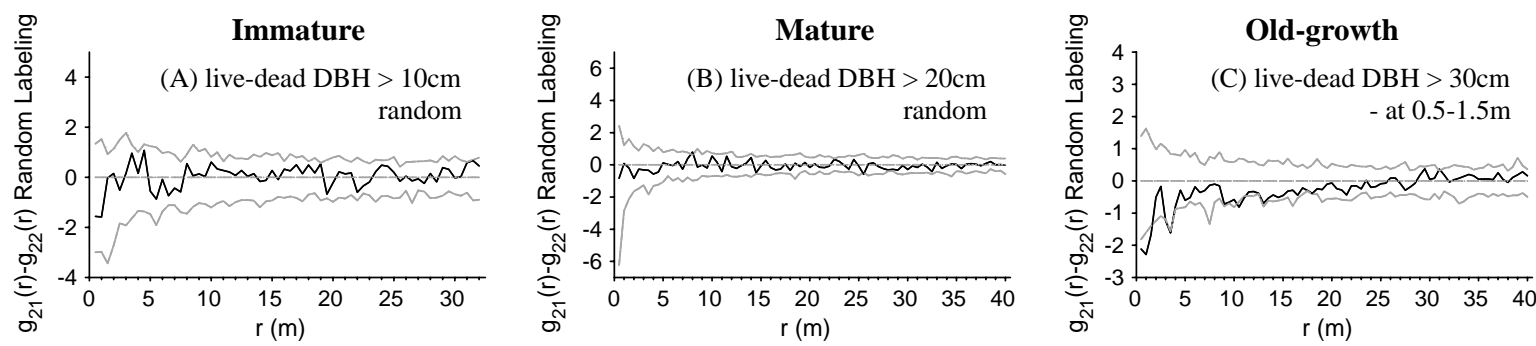

Fig. 6. Bivariate random labeling $\left(\mathrm{g}_{21}(\mathrm{r})-\mathrm{g}_{22}(\mathrm{r})\right)$ to investigate whether tree death (pattern 2) was a random process among larger trees in a plot. Under the null model "random labeling", $\mathrm{g}_{21}(\mathrm{r})-\mathrm{g}_{22}(\mathrm{r})=0$ (grey broken line). Analyses included trees with a DBH $>$ $10 \mathrm{~cm}$ in the immature plot (A), $>20 \mathrm{~cm}$ in the mature plot (B), and $>30 \mathrm{~cm}$ in the old-growth plot (C).

resource depletion leds to density-dependent self-thinning and thereby to a non-random mortality of trees.

Despite the shift from aggregation to a random distribution of all (dead and live) Douglas-fir in the immature and mature plots, respectively, intra-specific mortality was not significantly different from random mortality. Of the three species, only surviving hemlock showed a more regular post-mortality pattern in the IM and MA plots. Self-thinning effects must have been strong for that species but were less important for Df and $\mathrm{Cw}$ in our sites. These findings were also supported by comparing the mortalities in conspecific and heterospecific neighborhoods. Of the three species, only $\mathrm{Hw}$ showed a significantly higher mortality rate in conspecific than in heterospecific neighbourhoods (Table 4A).

Although, comparing pre- and post-mortality patterns is a strong approach in detecting competition, a single plot only represents a snap-shot analysis. Possibly, the snap-shot within the immature plot does not contain information from a sufficiently long time period to capture the signature of self-thinning. In our old-growth plot, mortality of Df was clustered, leading to an even more aggregated pattern of live trees. This deviation from random mortality is again opposite to the pattern of the old-growth forest studied by $\mathrm{He}$ and Duncan (2000), who found Df to shift towards a more regular distribution. It is likely that in our study sites intraspecific competition was relatively important for recruiting Df in gaps of the OG plot (Fig. 2A), but that there were also facilitating effects at the same time, leading to an increased aggregation of surviving Df. In ecological studies, the concept of facilitation has been often neglected and negative interactions have been overemphasized but, for example, in harsh terrestrial environments high seedling densities can increase growth and survivorship (Bruno et al. 2003). A low mortality of just $24 \%$ in conspecific Df as compared to $51 \%$ within heterospecifics in the OG plot supports this assumption. For shade-intolerant pioneer Douglas-fir it is almost impossible to regenerate under the out-shading canopy of late-successional colonizers such as hemlock and redcedar (Franklin and DeBell 1988, Spies et al. 1990). Since regeneration of Df in old-growth is only sufficient under suitable gaps and under more similar and lighttransmitting crowns within conspecifics, facilitation within Df could be important and may reduce this thinning process.

\section{Inter-specific competition}

In temperate forests a fundamental trade-off exists for the growth rate in high light, which is correlated with good seed dispersal, versus the survival rate in shade (Kobe et al. 1995, Silvertown 2004). In terms of an expected negative spatial association between shadeintolerant Df and shade-tolerant species, we found that inter-specific competition was not strong enough to lead to sufficient tree death and hence being detectable via spatial pattern analysis. None of the bivariate analyses found repulsion between Df and shade-tolerant species, not even when we did these analyses just for live trees (not shown).

However, there was important inter-specific competition when hemlock initially colonized the immature plot, as can be seen from correlation between tree size and nearest-neighbor distances. But competition of $\mathrm{Hw}$ within heterospecifics resulted in a significantly lower mortality than within conspecifics (Table 4A). This explains, why shade-tolerant $\mathrm{Hw}$ aggregates around $\mathrm{Df}$ in the immature plot although inter-specific competition is important. As a late-successional species, hemlock survival appears highly adapted to competition within heterospecifics (but not within conspecifics), thus to replacing the pioneer Douglas-fir. In contrast, survival of Douglas-fir within hetero- and conspecifics was not significantly different, neither in the immature nor in the mature plot, pointing to its strength as a pioneer that equally withstands intra- and inter-specific competition in the first succession phases.

Direct competitive interaction between the species strongly declined with increasing stand age (Fig. 2C). Here, spatial niche separation stabilized the coexistence of species towards older succession stages as is also indicated by the increase in spatial segregation of the species (Pielou's $\mathrm{S}$ in Table 3). The spatial niche separation does not need to be a direct result of inter- 
specific competition, because it can also be caused by micro-habitat heterogeneity such as the variability in forest-floor micro-relief (Duncan 1991). A recent study on Vancouver Island has shown that redcedar has a greater proportion of fine roots in the lower soil horizons than hemlock and that such spatial resource partitioning may be a mode to avoid direct inter-specific competition (Bennett et al. 2002). Hw has usually stronger interspecific effects on $\mathrm{Cw}$ than vice versa (Weber et al. 2003, Canham et al. 2004), but in this dry chronosequence Hw was probably physiologically disadvantaged and $\mathrm{Cw}$ was favored due to its better root penetration (Burns and Honkala 1990).

The different mortalities of species may also reflect different survival and dispersal strategies. Our results suggest that western hemlock seems to follow a "seedflooding strategy" with generally high mortality during initial colonization. This initial high mortality is primarily attributed to its lower survivial within conspecifics. These findings are supported by results from interior British Columbia, where the abundance of hemlock was always highest of all species under a gradient from closed to fully open canopy although overall mortalities were relatively high, too (Coates 2002). In contrast, redcedar is spatially much more selective as indicated by the consistently highest segregation index within a plot. This favored its survival during initial colonization of the mature plot but such a spatially confined strategy would be at the cost of missing favorable gaps during critical temporal changes in the forest structure and hence at the cost of not being dominant in older succession stages. Also, the best place for early establishment is not necessarily the best place for survival and growth. Coates (2002) has shown that tree abundance and composition was rather controlled by differentiation among growth and survival niches than by regeneration niches. Hence, the strength of hemlock as a successful colonizer may be attributed to a seed-flooding strategy whereby it not only increases the risk of mortality, primarily within conspecifics, but also the chance of reaching suitable survival niches within heterospecifics.

Once the trees have reached the upper canopy layer, mortality of large trees was spatially randomly distributed. Only in old-growth there was a spatial correlation of dead trees at very small scales, but this was only observed in certain smaller size-classes. Hence, competition or other mortality inducing processes did not affect the pattern of large trees of the overstory.

In summary, our study highlights the importance of spatial resource partitioning as a mode to avoid direct competitive interaction during succession. It emphasizes that late-successional species may initially exhibit strong inter-specific competition but their strength lies in a relatively high survival rate during competition which is mediated by micro-habitat heterogeneity.
Acknowledgements - This research was fully supported by the Pacific Forestry Centre of the Canadian Forest Service. The work was conducted during the visit of SG to the Dept of Renewable Resources, Univ. of Alberta.

\section{References}

Bailey, T. C. and Gatrell, A. C. 1998. Interactive spatial data analysis. - Longman.

Bennett, J. N. et al. 2002. Vertical fine root distributions of western redcedar, western hemlock, and salal in oldgrowth cedar-hemlock forests on northern Vancouver Island. - Can. J. For. Res. 32: 1208-1216.

Bruno, J. F. et al. 2003. Inclusion of facilitation into ecological theory. - Trends Ecol. Evol. 18: 119-125.

Burns, R. M. and Honkala, B. H. 1990. Silvics of North America: 1. conifers. - Agriculture Handbook 654, U.S. Dept Agricult.

Canham, C. D. et al. 2004. A neighborhood analysis of canopy tree competition: effects of shading versus crowding. - Can. J. For. Res. 34: 778-787.

Chen, J. et al. 2004. Spatial relationship of biomass and species distribution in an old-growth Pseudotsuga-Tsuga forest. - For. Sci. 50: 364-375.

Coates, K. D. 2002. Tree recruitment in gaps of various size, clearcuts and undisturbed mixed forest of interior British Columbia, Canada. - For. Ecol. Manage. 155: 387-398.

Condit, R. et al. 2000. Spatial patterns in the distribution of tropical tree species. - Science 288: 1414-1418.

Dale, M. R. T. et al. 2002. Conceptual and mathematical relationships among methods for spatial analysis. - Ecography 25: $558-577$.

Diggle, P. J. and Chetwynd, A. G. 1991. Second-order analysis of spatial clustering for inhomogeneous populations. - Biometrics 47: 1155-1163.

Dovčiak, M. et al. 2001. Discordance in spatial patterns of white pine (Pinus strobus) size-classes in a patchy nearboreal forest. - J. Ecol. 89: 280-291.

Duncan, R. P. 1991. Competition and the coexistence of species in a mixed podocarp stand. - J. Ecol. 79: 1073-1084.

Fang, W. 2005. Spatial analysis of an invasion front of Acer platanoides: dynamic inferences from static data. - Ecography 28: 283-294.

Ford, E. D. 1975. Competition and stand structure in some even-aged plant monocultures. - J. Ecol. 63: 311-333.

Franklin, J. F. and DeBell, D. S. 1988. Thirty-six years of tree population change in an old-growth Pseudotsuga-Tsuga forest. - Can. J. For. Res. 18: 633-639.

Green, R. N. and Klinka, K. 1994. A field guide to site identification and interpretation for the Vancouver Forest Region. -Land Manage. Handbook. No. 28, B.C. Min. For.

Harms, K. E. et al. 2001. Habitat associations of trees and shrubs in a 50-ha neotropical forest plot. - J. Ecol. 89: $947-$ 959.

He, F. and Duncan, R. P. 2000. Density-dependent effects on tree survival in an old-growth Douglas fir forest. - J. Ecol. 88: $676-688$.

He, F. and Legendre, P. 2002. Species diversity patterns derived from species-area models. - Ecology 83: 1185-1198.

Keeton, W. S. and Franklin, J. F. 2005. Do remnant old-growth trees accelerate rates of succession in mature Douglas-fir forest? - Ecol. Monogr. 75: 103-118.

Kenkel, N. C. 1988. Patterns of self-thinning in jack pine: testing the random mortality hypothesis. - Ecology 69: 1017-1024.

Kint, V. et al. 2003. Spatial methods for quantifying forest stand structure development: a comparison between nearestneighbor indices and variogram analysis. - For. Sci. 49: 36-49. 
Kobe, R. K. et al. 1995. Juvenile tree survivorship as a component of shade tolerance. - Ecol. Appl. 5: 517-532.

Kokkila, T. et al. 2002. A method for generating stand structures using Gibbs marked point process. - Silva Fenn. 36: 265-277.

Lertzman, K. P. et al. 1996. Canopy gaps and the landscape mosaic in a coastal temperate rain forest. - Ecology 77: $1254-1270$.

Mast, J. N. and Veblen, T. T. 1999. Tree spatial patterns and stand development along the pine-grassland ecotone in the Colorado Front Range. - Can. J. For. Res. 29: 575-584.

Mateu, J. et al. 1998. The spatial pattern of a forest ecosystem. - Ecol. Modell. 108: 163-174.

McDonald, R. I. et al. 2003. Spatial pattern of Quercus regeneration limitation and Acer rubrum invasion in a Piedmont forest. - J. Veg. Sci. 14: 441-450.

Moravie, M.-A. and Robert, A. 2003. A model to assess relationships between forest dynamics and spatial structure. - J. Veg. Sci. 14: 823-834.

Newton, P. F. and Jolliffe, P. A. 1998. Assessing processes of intraspecific competition within spatially heterogeneous black spruce stands. - Can. J. For. Res. 28: 259-275.

North, M. et al. 2004. Forest stand structure and pattern of oldgrowth western hemlock/Douglas-fir and mixed-conifer forests. - For. Sci. 50: 299-311.

Peterson, C. J. and Squiers, E. R. 1995. An unexpected change in spatial pattern across 10 years in an aspen-white-pine forest. - J. Ecol. 83: 847-855.

Pielou, E. C. 1961. Segregation and symmetry in two-species populations as studies by nearest-neighbour relationships. - J. Ecol. 49: 255-269.

Pielou, E. C. 1962. The use of plant-to-neighbour distances for the detection of competition. - J. Ecol. 50: 357-367.

Plotkin, J. B. et al. 2000. Species-area curves, spatial aggregation, and habitat specialization in tropical forest. $-\mathbf{J}$. Theor. Biol. 207: 81-99.

Ripley, B. D. 1976. The second-order analysis of stationary point processes. - J. Appl. Prob. 13: 255-266.

Schurr, F. M. et al. 2004. Spatial pattern formation in semi-arid shrubland: a priori predicted versus observed pattern characteristics. - Plant Ecol. 173: 271-282.

Shackleton, C. 2002. Nearest-neighbour analysis and the prevalence of woody plant competition in South African savannas. - Plant Ecol. 158: 65-76.
Silvertown, J. 2004. Plant coexistence and the niche. - Trends Ecol. Evol. 19: 605-611.

Simard, S. W. and Sachs, D. L. 2004. Assessment of interspecific competition using relative height and distance indices in an age sequence of seral interior cedar-hemlock forests in British Columbia. - Can. J. For. Res. 34: 1228-1240.

Spies, T. A. et al. 1990. Canopy gaps in Douglas-fir forests of the Cascade Mountains. - Can. J. For. Res. 20: 649-658.

Sterner, R. W. et al. 1986. Testing for life historical changes in spatial patterns of four tropical tree species. - J. Ecol. 74: 621-633.

Stoll, P. and Bergius, E. 2005. Pattern and process: competition causes regular spacing of individuals within plant populations. - J. Ecol. 93: 395-403.

Stoyan, D. and Stoyan, H. 1994. Fractals, random shapes and point fields. Methods of geometrical statistics. - Wiley.

Stoyan, D. and Penttinen, A. 2000. Recent applications of point process methods in forestry statistics. - Stat. Sci. 15: $61-78$.

Trofymow, J. A. et al. 1997. Chronosequences for research into the effects of converting coastal British Columbia oldgrowth forests to managed forests: an establishment report. - Can. For. Serv., BC-X- 374.

Weber, A. et al. 2003. Factors limiting the early survivorship of Thuja plicata on northern Vancouver Island, British Columbia. - Can. J. For. Res. 33: 854-861.

Welden, C. W. and Slauson, W. L. 1986. The intensity of competition versus its importance: an overlooked distinction and some implications. - Q. Rev. Biol. 61: 23-44.

Welden, C. W. et al. 1988. Competition and abiotic stress among trees and shrubs in northwest Colorado. - Ecology 69: $1566-1577$.

Wiegand, K. et al. 2000. Do spatial effects play a role in the spatial distribution of desert-dwelling Acacia raddiana? - $\mathbf{J}$. Veg. Sci. 11: 473-484.

Wiegand, T. and Moloney, K. A. 2004. Rings, circles, and nullmodels for point pattern analysis in ecology. - Oikos 104: 209-229.

Wolf, A. 2005. Fifty year record of change in tree spatial patterns within a mixed deciduous forest. - For. Ecol. Manage. 215: 212-223.

Subject Editor: Jens-Christian Svenning. 